\title{
Foraminifera Isotope Reequilibration Biases Paleotemperature Records
}

\author{
ARTHUR ADAMS ${ }^{1}$, LUKAS P. BAUMGARTNER ${ }^{2}$, \\ TORSTEN VENNEMANN ${ }^{2}$, DAMIEN DAVAL ${ }^{3}$, SYLVAIN \\ BERNARD $^{4}$, DEYANIRA CISNEROS-LAZARO ${ }^{5}$, JINMING \\ GUO $^{5}$, ALAIN BARONNET ${ }^{6}$, OLIVIER GRAUBY, \\ STOLARSKI JAREK ${ }^{7}$ AND ANDERS MEIBOM ${ }^{5}$ \\ ${ }^{1}$ EPFL \\ ${ }^{2}$ University of Lausanne \\ ${ }^{3}$ University of Strasbourg \\ ${ }^{4}$ IMPMC CNRS/Sorbonne Université/MNHN \\ ${ }^{5}$ École polytechnique fédérale de Lausanne \\ ${ }^{6} \mathrm{CINaM}$ \\ ${ }^{7}$ Polish Academy of Sciences \\ Presenting Author: arthur.adams@epfl.ch
}

Oxygen isotope compositions of calcitic foraminifera tests are commonly used as proxies of surface and deep paleoseawater temperatures from the late-Mesozoic to the present. While it has been known that recrystallized foraminifera can clearly falsify the isotopic compositions measured, it is still a debate whether isotopic exchange is also possible even if no evidence of changes in the foraminifera ultrastructures are noted. Recent studies have demonstrated that modern and fossil foraminifera tests can rapidly exchange isotopes with diagenetic fluids at low temperatures with no associated changes in the foraminifera ultrastructure $[1,2]$. This implies that paleoseawater temperature reconstructions may incorporate a diagenetic bias from the inclusion of structurally pristine but isotopically reequilibrated foraminifera.

To quantify, and correct this potential isotopic bias, we simulated diagenesis by exposing modern foraminifera tests to ${ }^{18} \mathrm{O}$-enriched, calcite saturated $(\mathrm{SI}=1)$ artificial seawater for 2 hours to 54 days at 30 to $90{ }^{\circ} \mathrm{C}$. Scanning electron microscopy imaging confirmed no observable change in test ultrastructure after experiments. Bulk isotope measurements show that isotope exchange has a linear relationship with respect to the square root of time and that foraminifera tests may be composed of two isotopic reservoirs: (1) a smaller but rapidly exchangeable reservoir and (2) a larger reservoir capable of slow but continuous isotope exchange. In the experiments, the combined effect of these reservoirs resulted in an exchange of $>1 \%$ of the oxygen in a foraminifera test with the surrounding pore fluids in only 54 days, which is an exchange rate that would create substantial bias in the calculated paleotemperatures from fossil foraminifera older than about 5 million years.

Our results show that foraminifera tests and potentially other biocalcites may substantially change their isotopic composition with pore fluids at low temperatures and short timescales. Hence the precision of the foraminifera oxygen isotope thermometer for paleoseawater temperature reconstructions should be reassessed and potentially corrected for this diagenetic exchange bias.

[1] Bernard et al. (2017), Nature Communications, 8(1), 1-10.

[2] Chanda et al. (2019), Earth and Planetary Science Letters, $506,428-440$. 